Article

\title{
Polymer/BiOBr-Modified Gauze as a Dual-Functional Membrane for Heavy Metal Removal and Photocatalytic Dye Decolorization
}

\author{
Chi-Jung Chang ${ }^{1, *}$, Pei-Yao Chao ${ }^{1}$, Chen-Yi Chou ${ }^{1}$, Ying-Jen Chen ${ }^{1}$ and Chih-Feng Huang ${ }^{2}$ \\ 1 Department of Chemical Engineering, Feng Chia University, 100, Wenhwa Road, Seatwen, \\ Taichung 40724, Taiwan; happinese_cat@yahoo.com.tw (P.-Y.C.); jennychou830404@gmail.com (C.-Y.C.); \\ a7071272@gmail.com (Y.J.C.) \\ 2 Department of Chemical Engineering, i-Center for Advanced Science and Technology (ICAST), \\ National Chung Hsing University, Eng Bld 3, 250 Kuo Kuang Road, Taichung 40227, Taiwan; \\ huangcf@nchu.edu.tw \\ * Correspondence: changcj@fcu.edu.tw
}

Received: 20 August 2020; Accepted: 11 September 2020; Published: 13 September 2020

\begin{abstract}
It is crucial to remove heavy metals and dyes before discharging industrial effluents. Gauze substrate was surface-modified by coating with a polymeric adsorbent and a spray coating of $\mathrm{BiOBr}$ photocatalyst to develop a novel dual-functional membrane, polymer/BiOBr-modified gauze, for water remediation. The polymeric adsorbent was crosslinked to prevent the dissolving of the adsorbent during operation in contaminated water. The morphology and surface chemistry of the modified gauze were characterized before and after the adsorption of $\mathrm{Ni}^{2+}$. The surface wettability, isotherms, and kinetics of $\mathrm{Ni}^{2+}$ adsorption were studied. We also studied the effect of $\mathrm{pH}$, initial $\mathrm{Ni}^{2+}$ concentration, monomer molar ratio, and monomer chemical structure on the $\mathrm{Ni}^{2+}$ adsorption capacity. To achieve a high $\mathrm{Ni}^{2+}$ adsorption capacity and good photocatalytic decolorization activity, the amount of decorated $\mathrm{BiOBr}$ was tuned by changing the spray-coating time to optimize the exposed $\mathrm{BiOBr}$ and polymer on the surface. The optimized dual-functional membrane PB20 possesses excellent adsorption capacity $\left(650 \mathrm{mg} \mathrm{g}^{-1}\right)$ for $\mathrm{Ni}^{2+}$ ions and photocatalytic decolorization activity (100\% degradation of RhB within $7 \mathrm{~min}$ ). Decorating the optimized amount of $\mathrm{BiOBr}$ on the surface can introduce photocatalytic decolorization activity without sacrificing the adsorption capacity for $\mathrm{Ni}^{2+}$.
\end{abstract}

Keywords: adsorbent; photocatalyst; heavy metal; dye; BiOBr; polyethyleneimine

\section{Introduction}

Heavy metal ions in industrial effluents have been a serious problem. Soluble heavy metal ions will accumulate in living organisms, leading to some diseases. Several heavy metals are found in the effluents of many industries. Among them, nickel is a transition metal with moderate toxicity. It can cause skin disorders, such as allergic reactions and dermatitis. Additionally, chronic exposure may result in some problems, such as pulmonary fibrosis and cardiovascular diseases [1-3]. Therefore, toxic heavy metal ions should be removed from industrial effluents to minimize the environmental impact of effluents toward water bodies. Furthermore, colorants (dye and pigment) are widely utilized in textile, paper, leather, polymer, cosmetics, food, and chemical industries $[4,5]$. There has been an urgent need to remove heavy metals and dyes in industrial wastewater by appropriate processes [6-11].

At present, various techniques, such as ion-exchange [12,13], chemical precipitation [14,15], photocatalytic degradation [16-18], Fenton process [19], membrane separation [20-22], and adsorption [23-25], etc., have been developed for the removal of single pollutants (either heavy 
metal or dye). Among them, adsorption is still an effective method because it is efficient, low cost, and easy to handle. With the use of dyes and heavy metals in various industries, dyes and heavy metals were reported to coexist in industrial effluents $[26,27]$. Both heavy metals and dyes have significant ecological effects on our environment due to their toxicity, persistence, and bioaccumulation. It is very important to remove heavy metals and dyes before discharging industrial effluents [28]. Effective removal of both hazardous dyes and potentially toxic metals is not easy work due to the different physical and chemical properties of dyes and heavy metals, such as the treatment of $\mathrm{MO}$ and $\mathrm{Pb}$ (II) [29]. A great deal of effort has been devoted to the development of effective, facile, and environmentally friendly approaches for the simultaneous removal of heavy metals and dyes from contaminated water. Skold et al. reported the simultaneous metal and organic (perchloroethylene, PCE) complexation by (carboxymethyl)- $\beta$-cyclodextrin [30]. Wan et al. [31] reported that manganese-oxidizing bacteria consortia exhibited effective removal of $\mathrm{Mn}(\mathrm{II})$ in harsh conditions. Manganese-oxidizing bacteria and biogenic Mn oxides are useful in the remediation of pollution containing organic pollutants and heavy metal ions.

Nowadays, there are some studies about the removal of heavy metals and dyes from wastewater [32-35]. Inorganic nanomaterial/polymer composites have attracted much attention due to the increasing demand for new materials with improved photocatalytic, adhesion, mechanical, photoconductive, adhesion, and thermal properties [36-44]. Liu et al. reported that silver nanoparticles and polypyrrole-modified $\mathrm{BiOBr}$ with a Z-scheme heterostructure acted as a composite catalyst that possesses outstanding photocatalytic activity and stability [45]. Additionally, polyethyleneimine (PEI) has excellent metal chelation abilities because of the large amount of $-\mathrm{NH}_{2}$ groups on its molecular chain $[46,47]$. Wang et al. [48] found that polyethyleneimine-functionalized ion-imprinted hydrogel was useful for the removal of $\mathrm{Cu}$ (II).

In this study, we attempted to remove dyes and heavy metals by adsorption and photocatalysis reactions, respectively, using inorganic nanomaterial/polymer composites (polymer/BiOBr-modified gauze). We used a crosslinked polymer consisting of hydrophilic diepoxy (PEGDE), a crosslinking agent (PEI), and diamine (TETA) to obtain a polymer-modified gauze, and then functionalized with $\mathrm{BiOBr}$ through spray coating to prepare the polymer/BiOBr-modified gauze as a dual functional membrane that possesses a high adsorption capacity for $\mathrm{Ni}^{2+}$ ion and good photocatalytic decolorization activity. The morphology and surface chemistry of the modified gauze were characterized before and after the adsorption of $\mathrm{Ni}^{2+}$. The surface wettability, isotherms, and kinetics of adsorption were studied. We also studied the effect of $\mathrm{pH}$, initial $\mathrm{Ni}^{2+}$ concentration, monomer molar ratio, and monomer chemical structure on the $\mathrm{Ni}^{2+}$ adsorption capacity. To achieve a high $\mathrm{Ni}^{2+}$ adsorption capacity and good photocatalytic decolorization activity, the amount of decorated $\mathrm{BiOBr}$ was tuned by changing the spray-coating time to optimize the exposed $\mathrm{BiOBr}$ and polymer on the surface.

\section{Materials and Methods}

Gauze substrate (100\% Rayon) was coated with an aqueous solution of hydrophilic monomers, including diepoxy (poly(ethylene glycol) diglycidyl ether, (PEGDE)), diamine (triethylenetetramine, (TETA)), and a crosslinking agent (polyethyleneimine (PEI)). However, since all monomers are well soluble in water, the coated samples were thermally cured to fix the polymeric adsorbent on the gauze by an amine-epoxy crosslinking reaction to prevent the dissolving of adsorbent during operation in contaminated water. Then, $\mathrm{BiOBr}$ was dispersed in the above-mentioned solution and deposited on the polymer-modified gauze by spray-coating and thermal curing to obtain the polymer/BiOBr-modified gauze as a dual functional membrane that possesses high adsorption capacity for $\mathrm{Ni}^{2+}$ ion and good photocatalytic decolorization activity.

\subsection{Materials}

Poly(ethylene glycol) diglycidyl ether (PEGDE), and triethylenetetramine (TETA) were purchased from Aldrich (St. Louis, MO, USA). Polyethylenimine (PEI) was supplied by Alfa-Aesar 
(Tewksbury, MA, USA). 1,4-bis(3-aminopropyl)-piperazine (BAP) was materials purchased from TCI (Fukaya City, Japan).

\subsection{Preparation of $\mathrm{BiOBr}$}

$\mathrm{BiOBr}$ was prepared by a solvothermal method. First, $0.12 \mathrm{~g}$ of bismuth nitrate was added to the mixed solution containing $5 \mathrm{~mL}$ of ethylene glycol and $35 \mathrm{~mL}$ of isopropanol. Then, $0.18 \mathrm{~g}$ of cetyltrimethylammonium bromide (CTAB) was added. The solution was stirred for $60 \mathrm{~min}$ and then transferred to a Teflon-lined vessel. The reaction was carried out at $145^{\circ} \mathrm{C}$ for $12 \mathrm{~h}$. After being washed in deionized water and ethanol solution, filtration, and drying, bismuth bromide powder (BiOBr) can be obtained.

\subsection{Coating of Immobilized Adsorbents on gauze@PEI0.4/PEGDE1/TETA0.6}

Polyethylenimine (PEI, 0.4 mmole), poly(ethylene glycol) diglycidyl ether (PEGDE, 1 mmole), and triethylenetetramine (TETA, $0.6 \mathrm{mmole}$ ) are all dissolved in DI water to prepare a solution with a solid content of $10 \mathrm{wt} \%$. A $4 \mathrm{~cm} \times 4 \mathrm{~cm}$ gauze is dip-coated in the above-mentioned solution, then thermal cured at $115^{\circ} \mathrm{C}$ for an hour. The polymer-modified gauze is designated as gauze@PEI $/ \mathrm{PEGDE}_{\mathrm{y}} / \mathrm{TETA}_{\mathrm{z}}$ where $\mathrm{x}, \mathrm{y}$, and $\mathrm{z}$ mean the mole feed ratio of PEI, PEDGE, and TETA monomers, respectively.

\subsection{Preparation of Polymer/BiOBr-modified Gauze}

The prepared BiOBr suspension (5 $\mathrm{wt} \%$ in ethanol) was loaded in an airbrush (Sparmax DH-103) with a 0.3-mm nozzle. Then, the suspension was spray-coated on the surface of the gauze@ adsorbent substrates $(4 \mathrm{~cm} \times 4 \mathrm{~cm})$ layer by layer. Three samples (PB10, PB20, PB30) were prepared by changing the time for spray coating $(10,20,30 \mathrm{~s})$. The samples were denoted as PBX. P means the polymer-modified gauze sample (gauze@ $\mathrm{PEI}_{0.4} / \mathrm{PEGDE}_{1} / \mathrm{TETA}_{0.6}$ ). $\mathrm{B}$ indicates $\mathrm{BiOBr}$ photocatalyst. $\mathrm{X}$ indicates the time for spray coating. The process for the preparation of polymer/BiOBr-modified gauze (Sections 2.3 and 2.4) is demonstrated in Scheme 1.

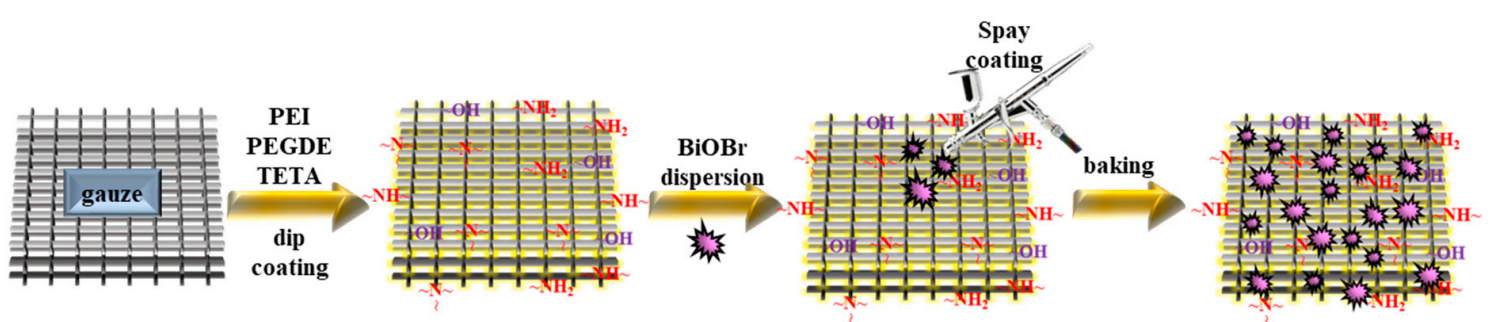

Scheme 1. Process for the preparation of polymer/BiOBr-modified gauze.

\subsection{Characterization of Modified Gauze}

A field emission scanning electron microscope (HITACH S-4800) was used to observe the surface textures and elemental analysis for samples. The conditions for mapping include acceleration voltage $15 \mathrm{kV}$, working distance $8 \mathrm{~mm}$. XPS (ULVAC-PHI, PHI 5000 Versa Probe) was used to investigate the surface chemistry of the samples. The $\mathrm{Ni}^{2+}$ contents in the solution were monitored by an ultraviolet-visible spectrophotometer (JASCO, V-770). The dynamic contact angles of the samples were monitored by the contact angle meter (CAM-100).

\subsection{Batch Adsorption Study}

The modified gauze $(4 \times 4 \mathrm{~cm})$ was immersed in an aqueous solution containing $\mathrm{Ni}^{2+}(1600 \mathrm{mg} / \mathrm{L})$ at room temperature for $90 \mathrm{~min}$. An aliquot of the solution was withdrawn from the reaction mixture. The residual $\mathrm{Ni}^{2+}$ content in the solution was determined by the UV-VIS spectrometer.

The capacity of $\mathrm{Ni}^{2+}$ adsorption was obtained from the equation [49]: 
Adsorption capacity

$$
(\mathrm{Qe})=\frac{\left(\mathrm{C}_{0}-\mathrm{C}_{\mathrm{e}}\right) \mathrm{V}}{\mathrm{m}}(\mathrm{mg} / \mathrm{g})
$$

where $m$ and $V$ are the weight of adsorbent $(\mathrm{g})$ and the volume of solution $(\mathrm{L})$, respectively. $\mathrm{C}_{\mathrm{e}}$ and $\mathrm{C}_{\mathrm{o}}$ are the final and initial ion concentrations $(\mathrm{mg} / \mathrm{L})$.

The adsorption kinetics was investigated by pseudo first or second-order models. The appropriateness of different models was determined by the correlation coefficient $\left(R^{2}\right)$. The model is more suitable if the $R^{2}$ value is closer to 1 . The equations for first order and second order are listed below [50]:

$$
\begin{gathered}
\log (\mathrm{Qe}-\mathrm{Qt})=\log \mathrm{Qe}-\mathrm{k}_{1} \mathrm{t} / 2.303 \\
1 /(\mathrm{Q}-\mathrm{Qt})=1 / \mathrm{Qe}+\mathrm{k}_{2} \mathrm{t}
\end{gathered}
$$

The adsorption between the residual and adsorbed metal ions in the solution during the adsorption process can be estimated by the adsorption isotherms using Langmuir and Freundlich models [51]. In this study, equilibrium isotherms are measured to evaluate the capacity of the adsorbent for the adsorption of $\mathrm{Ni}^{2+}$.

Langmuir adsorption assumes that the largest adsorption is related to a saturated surface monolayer of solute molecules on the adsorbent. The equation is listed as follows:

$$
1 / \mathrm{qe}=(1 / \mathrm{qm} \mathrm{kL}) 1 / \mathrm{Ce}+1 / \mathrm{qm}
$$

where $\mathrm{Ce}$, qm, qe, and $\mathrm{kL}$ represent the equilibrium concentration of metal ions $(\mathrm{mg} / \mathrm{L})$, monolayer adsorption capacity $(\mathrm{mg} / \mathrm{g})$, quantity of adsorbed metal ion $(\mathrm{mg} / \mathrm{g})$, and equilibrium Langmuir constant $(\mathrm{L} / \mathrm{mg})$, respectively.

At equilibrium, the amount of adsorbed adsorbate per unit mass of the adsorbent (qe) can be investigated by the Freundlich adsorption isotherm [52]:

$$
\log \mathrm{qe}=\log \mathrm{kF}+1 / \mathrm{nlog} \mathrm{Ce}
$$

where $\mathrm{n}$ and $\mathrm{kF}$ mean the values determined graphically, and Freundlich constants, respectively.

\subsection{Photocatalytic Activity}

Before the photocatalytic degradation test, the modified gauze $(4 \mathrm{~cm} \times 4 \mathrm{~cm})$ was immersed in the solution and stirred in the dark for $60 \mathrm{~min}$ to reach an adsorption-desorption equilibrium between the modified gauze and $\mathrm{RhB}$ dye. When the photocatalytic reaction began, $10 \mathrm{~mL}$ of aqueous $\mathrm{RhB}$ solution $(10 \mathrm{ppm})$ was stirred and kept at $30^{\circ} \mathrm{C}$ when irradiated by a Xe lamp. The change in concentration of RhB was monitored every $15 \mathrm{~min}$ by the UV-VIS spectrometer. The decolorization rate can be obtained as:

$$
\text { Decolorization }(\%)=\mathrm{C} / \mathrm{C}_{0} \times 100(\%)
$$

where $\mathrm{C}_{0}$ and $\mathrm{C}$ are the initial dye concentration and the dye concentration after light irradiation, respectively. The absorption peak intensity of $\mathrm{RhB}$ at $554 \mathrm{~nm}$ was measured to monitor its decolorization rate.

\section{Results and Discussion}

\subsection{The Removal of Heavy Metal Ions}

\subsubsection{Dynamic Contact Angle (DCA)}

Figure 1 shows the images of the dynamic contact angle test, revealing the time required for the complete wetting of water droplets on various polymer-coated gauze. All samples are hydrophilic. The water droplet penetrated the adsorbents (complete wetting) within a short 
period of time. The complete wetting time for different membranes gauze@PEI $\mathrm{P}_{0.4} / \mathrm{PEGDE}_{1} / \mathrm{TETA}_{0.6}$, gauze@PEI $0.2 / \mathrm{PEGDE}_{1} / \mathrm{TETA}_{0.8}$, and gauze@PEI $\mathrm{PE}_{0.2} / \mathrm{PEGDE}_{1} / \mathrm{BAP}_{0.8}$ is 4,16 , and $5 \mathrm{~s}$, respectively.

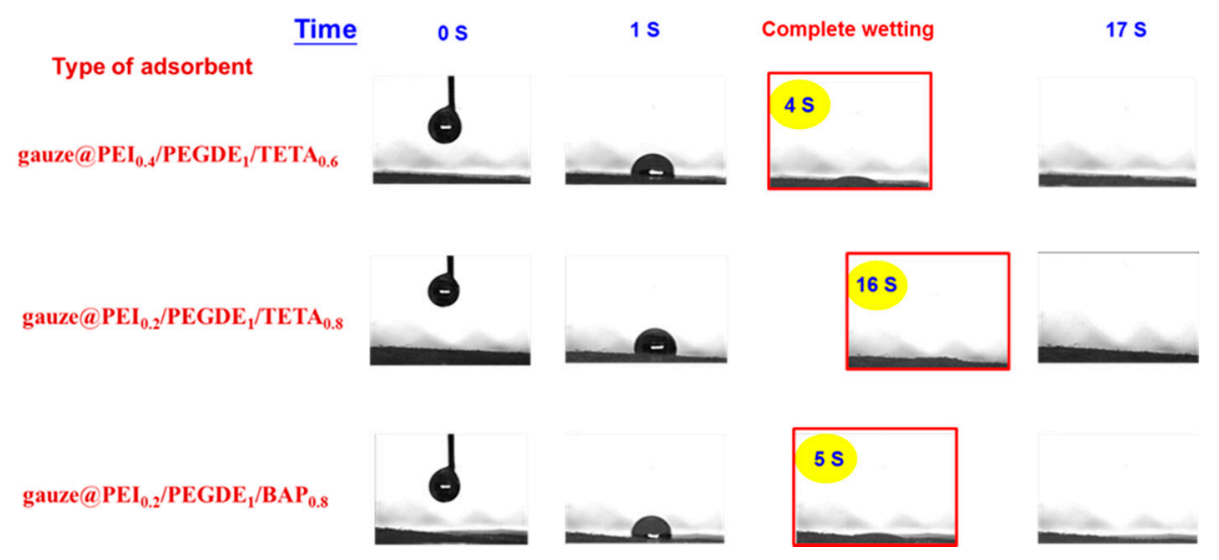

Figure 1. Images of the time required for the complete wetting of water droplet on various polymer-coated gauze.

However, the result highlighted that the dynamic wetting behavior for each adsorbent is different. For example, the time needed for complete wetting on gauze@PEI $\mathrm{P}_{0.2} / \mathrm{PEGDE}_{1} / \mathrm{TETA}_{0.8}(16 \mathrm{~s})$ is longer than that of gauze@PEI ${ }_{0.4} / \mathrm{PEGDE}_{1} / \mathrm{TETA}_{0.6}$, which only takes $4 \mathrm{~s}$. The longer time taken by gauze@PEI ${ }_{0.2} / \mathrm{PEGDE}_{1} / \mathrm{TETA}_{0.8}$ is ascribed to its lower mole ratio of PEI monomer than that in gauze@PEI $0.4 / \mathrm{PEGDE}_{1} / \mathrm{TETA}_{0.6}$. Furthermore, the dynamic contact angle also evidenced the effect of different types of amino monomer on the wettability of the adsorbents. Although both adsorbents have the same mole ratio of PEI, when TETA is replaced by BAP, the time required for complete wetting decreases significantly from the initial $16 \mathrm{~s}$ (gauze@PEI $\left.\mathrm{PL}_{0.2} / \mathrm{PEGDE}_{1} / \mathrm{TETA}_{0.8}\right)$ to $5 \mathrm{~s}$ (gauze@PEI $0.2 / \mathrm{PEGDE}_{1} / \mathrm{BAP}_{0.8}$ ).

\subsubsection{Charaterization of the Gauze@PEI $\mathrm{PI}_{0.4} / \mathrm{PEGDE}_{1} / \mathrm{TETA}_{0.6}$ (FESEM and Mapping)}

Figure 2 presents the SEM images of gauzes and its elemental distribution before and after adsorption. It is observed that there is a significant difference between pristine gauze (Figure 2a) and gauze@PEI $\mathrm{PL}_{0.4} / \mathrm{PEGDE}_{1} / \mathrm{TETA}_{0.6}$ (Figure $2 \mathrm{~b}$ ). Pristine gauze consists of stacks of fibers, thus leading to the presence of some interstitial voids. The SEM image of gauze@PEI $\mathrm{P}_{0.4} / \mathrm{PEGDE}_{1} / \mathrm{TETA}_{0.6}$ displayed that the presence of the $\mathrm{PEI}_{0.4} / \mathrm{PEGDE}_{1} / \mathrm{TETA}_{0.6}$ coating leads to an increase in the diameter of the coated fiber as well as fill up the interstitial voids. Additionally, the uniform surface of the gauze revealed that the adhesion between the coated polymeric adsorbent layer and gauze is good. The mapping imaging of $\mathrm{N}$ (Figure $2 \mathrm{~b}$ (iii)) showed that the amine functional group of the polymeric adsorbent was uniformly distributed on the gauze. Figure 3 shows the SEM images and elemental mapping of gauze@PEI $0.4 / \mathrm{PEGDE}_{1} / \mathrm{TETA}_{0.6}$. After the adsorption of $\mathrm{Ni}^{2+}$, the surface of the gauze became rough. The adsorption of $\mathrm{Ni}^{2+}$ significantly changed the surface morphology of the sample. Further, the results of elemental mapping confirmed the adsorption of nickel on the adsorbent layer of polymer-modified gauze. 


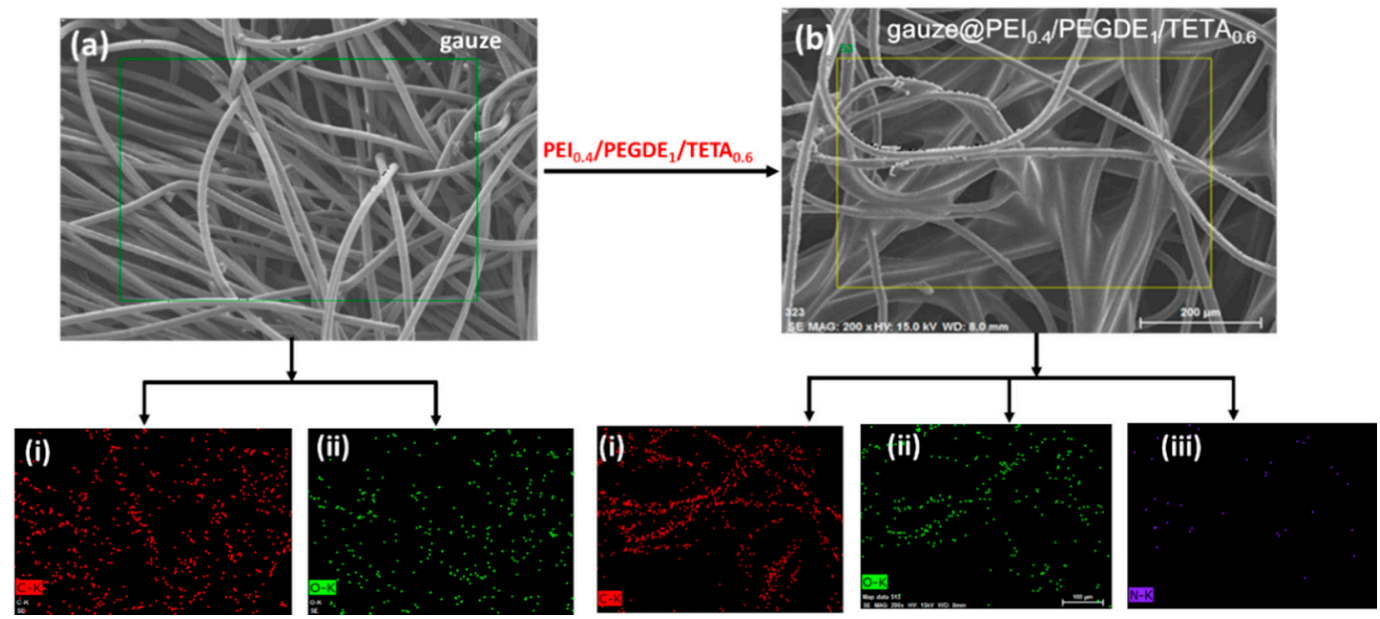

Figure 2. FESEM images of (a) pristine gauze and (b) gauze@PEI $\mathrm{P}_{0.4} / \mathrm{PEGDE}_{1} / \mathrm{TETA}_{0.6}$. Elemental C, O, and $\mathrm{N}$ mapping of the pristine gauze.

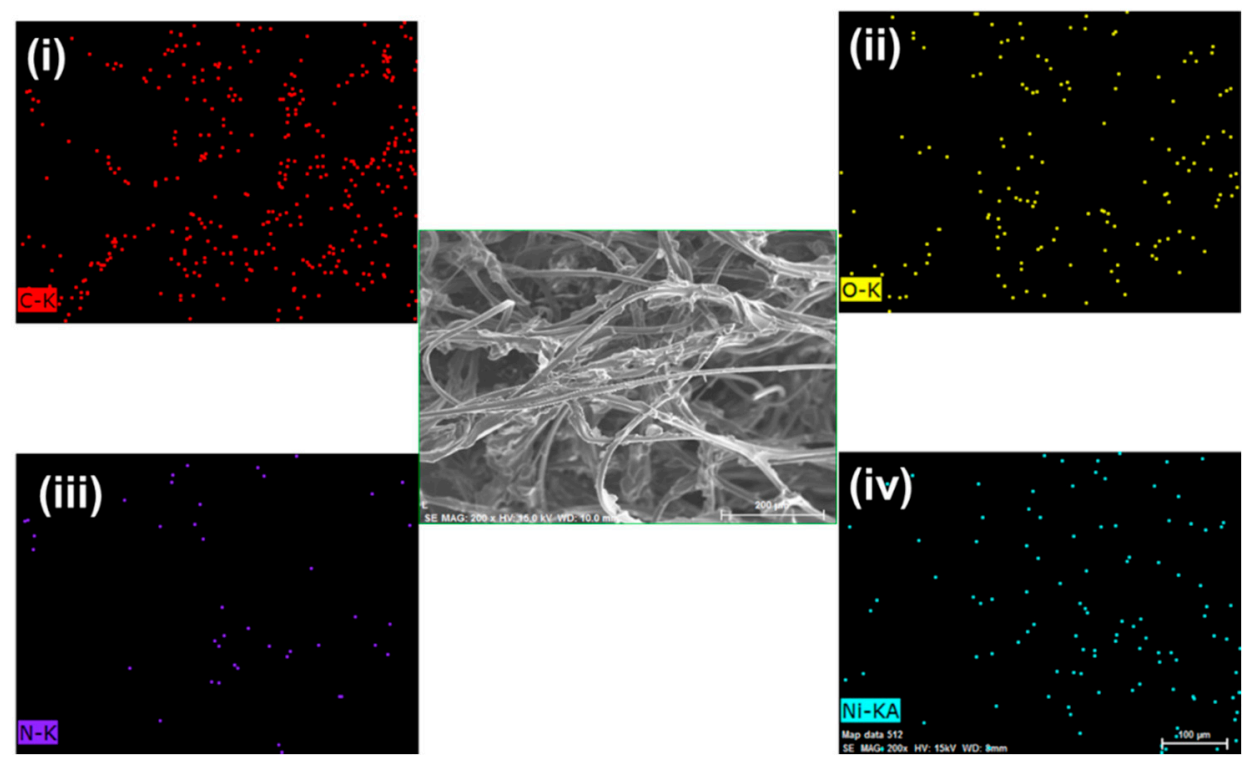

Figure 3. SEM image of $\mathrm{Ni}^{2+}$ adsorbed gauze@PEI ${ }_{0.4} / \mathrm{PEGDE}_{1} / \mathrm{TETA}_{0.6}$, and (i) $\mathrm{C}$, (ii) $\mathrm{O}$, (iii) $\mathrm{N}$, and (iv) $\mathrm{Ni}^{2+}$ mapping.

\subsubsection{XPS Spectra of Gauze@PEI $\mathrm{P}_{0.4} / \mathrm{PEGDE}_{1} / \mathrm{TETA}_{0.6}$}

The chemical compositions of the polymer-modified sample, gauze@PEI $\mathrm{P}_{0.4} / \mathrm{PEGDE}_{1} / \mathrm{TETA}_{0.6}$ are monitored by XPS. The wide-scan XPS spectra of pristine and $\mathrm{Ni}^{2+}$ adsorbed gauze@PEI $\mathrm{PL}_{0.4} / \mathrm{PEGDE}_{1} /$ TETA $_{0.6}$ are illustrated in Figure $4 a, b$, respectively. The C, O, and $\mathrm{N}$ elements were found in the XPS spectra of both gauzes, indicating the coating of polymeric adsorbent on the gauze. However, $\mathrm{Ni}$ is detected for the $\mathrm{Ni}^{2+}$-adsorbed sample (Figure $4 \mathrm{~b}$ ). Figure $4 \mathrm{c}-\mathrm{f}$ indicates the XPS spectra of elements $\mathrm{C}$, $\mathrm{N}$, and $\mathrm{O}$, respectively. The $\mathrm{C} 1 \mathrm{~s}$ peak at $283.8 \mathrm{eV}$ (Figure 4c) and a N 1s peak at $398 \mathrm{eV}$ (Figure 4d) indicated the presence of cross-linked polymeric adsorbent containing PEI and TETA. However, the characteristic peak of $\mathrm{N} 1 \mathrm{~s}$ is shifted towards larger binding energy of $398.7 \mathrm{eV}$ in the $\mathrm{Ni}^{2+}$-adsorbed sample (Figure 4d), confirming the successful chelation between $\mathrm{Ni}^{2+}$ ions and the amine group of PEI and TETA segments on the polymer chain. Figure 4e exhibits the binding energy around $531.5 \mathrm{eV}$ for $\mathrm{O} 1 \mathrm{~s}$ that is associated with the oxygen element in $\mathrm{C}-\mathrm{OH}$ in the samples. According to Figure 4e, the binding energy of $\mathrm{O} 1 \mathrm{~s}$ shifted towards $531 \mathrm{eV}$ for the gauze@PEI $\mathrm{P}_{0.4} / \mathrm{PEGDE}_{1} / \mathrm{TETA}_{0.6}$ after $\mathrm{Ni}^{2+}$ adsorption. This can be attributed to the decrease in electron density around oxygen atoms as they 
lose electrons that migrated to $\mathrm{Ni}^{2+}$ after the chelation between $\mathrm{OH}$ and $\mathrm{Ni}^{2+}$ [53]. The shift shows that, due to $\mathrm{Ni}^{2+}$ adsorption, the oxygen atom tends to exist in a more oxidized state. As shown in Figure $4 \mathrm{f}$, various $\mathrm{Ni}$ species can be interpreted in the spectrum of $\mathrm{Ni} 2 \mathrm{p}$ with a prominent peak at around $\sim 854.1 \mathrm{eV}$ for $\mathrm{Ni}(0)$ [54]. Additionally, it is also observed that $\mathrm{Ni}^{2+}$ is reduced to $\mathrm{Ni}(0)$ because of the coordination between $\mathrm{Ni}^{2+}$ and amine groups in TETA and PEI. The energy spectrum of the $\mathrm{Ni} 2 \mathrm{p}$ peak is shown clearly in Figure 4f. It shows a major peak at $857 \mathrm{eV}$, indicating the presence of oxidized Ni. Furthermore, there are a few more minor peaks observed at $862.1 \mathrm{eV}, 874.2 \mathrm{eV}, 879.1 \mathrm{eV}$, 881.2 , and $889 \mathrm{eV}$, which are attributed to the presence of various $\mathrm{Ni}$ oxide species, such as $\mathrm{Ni}(\mathrm{OH})_{2}$ and $\mathrm{NiOOH}$ [55]. Thus, the results revealed that $\mathrm{Ni}^{2+}$ acquired electrons and formed a complex between $\mathrm{Ni}$ and $\mathrm{NH}_{2}$.
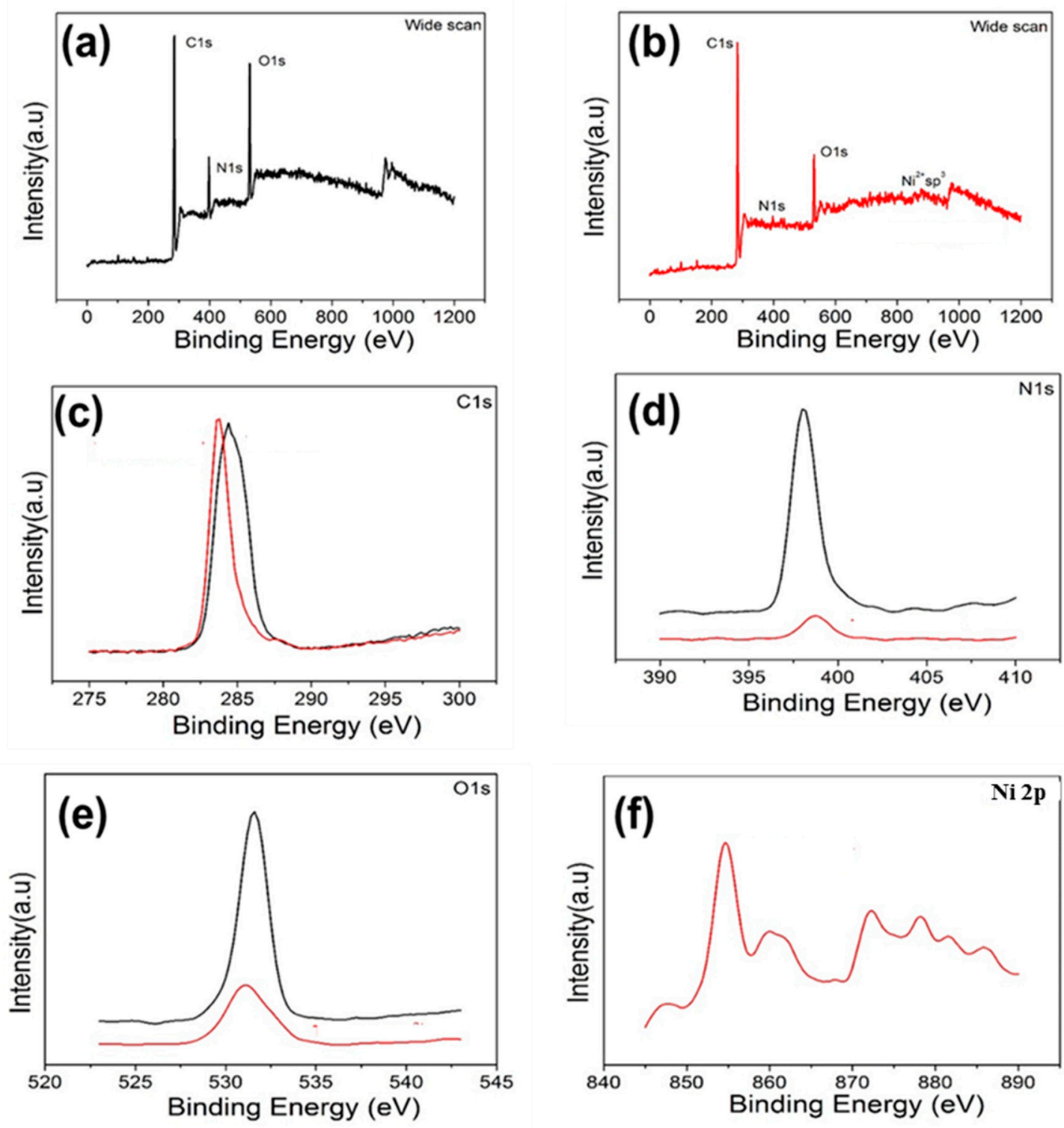

Figure 4. Wide-scan XPS spectra of (a) gauze@PEI $0.4 / \mathrm{PEGDE}_{1} / \mathrm{TETA}_{0.6}$ and (b) $\mathrm{Ni}^{2+}$ adsorbed gauze@PEI $0.4 / \mathrm{PEGDE}_{1} / \mathrm{TETA}_{0.6}$. XPS spectra of (c) C 1s; (d) N 1s; (e) O 1s, and (f) $\mathrm{Ni} 2 \mathrm{p}$ regions in gauze@PEI $\mathrm{P}_{0.4} / \mathrm{PEGDE}_{1} / \mathrm{TETA}_{0.6}$ (black line) and gauze@PEI $0.4 / \mathrm{PEGDE}_{1} / \mathrm{TETA}_{0.6}$ after $\mathrm{Ni}^{2+}$ adsorption (red line). 


\subsubsection{Effect of Solution $\mathrm{pH}$ toward the Adsorption Process}

The effects of the $\mathrm{pH}$ of the solution on $\mathrm{Ni}^{2+}$ adsorption and desorption performance by polymeric adsorbent-coated gauze were investigated. As shown in Figure $5 \mathrm{a}$, the influence of $\mathrm{pH}$ on the $\mathrm{Ni}^{2+}$ adsorption is determined by a solution with various $\mathrm{pH}$ (from 2 to 7). Our result demonstrated that the adsorption capacity of $\mathrm{Ni}^{2+}$ varies with increasing $\mathrm{pH}$ value. The lower $\mathrm{Ni}^{2+}$ adsorption capacity at low $\mathrm{pH}(\mathrm{pH} 2-4)$ is ascribed to the larger positive charge density of the polymeric adsorbent due to the protonation reaction $\left(\mathrm{H}^{+}+\mathrm{NH}_{2} \rightarrow \mathrm{NH}_{3}{ }^{+}\right)$, thus increasing the repulsion between $\mathrm{Ni}^{2+}$ ions. Additionally, the lower $\mathrm{pH}$ of the solution leads to great competition among metal ions with an abundance of hydrogen ions. Similar results were also reported by Chang and coworkers [56]. For acidic solutions, the transformation of $-\mathrm{NH}_{2}$ into $\mathrm{NH}^{3+}$ causes a few $-\mathrm{NH}_{2}$ sites on the surface of the adsorbents that can react with heavy metal ions. With the increase in $\mathrm{pH}$ value, the adsorption of $\mathrm{Ni}^{2+}$ also increases. The maximum uptake of $\mathrm{Ni}^{2+}$ ions is achieved at $\mathrm{pH}$ 7. This results from the deprotonation of more functional groups that are accessible to heavy metal ions at higher $\mathrm{pH}$ values when compared to lower $\mathrm{pH}$. A further increase in $\mathrm{pH}$ leads to the formation of precipitates. Hence, the remaining experiments in this study are carried out at $\mathrm{pH}=7.0$.
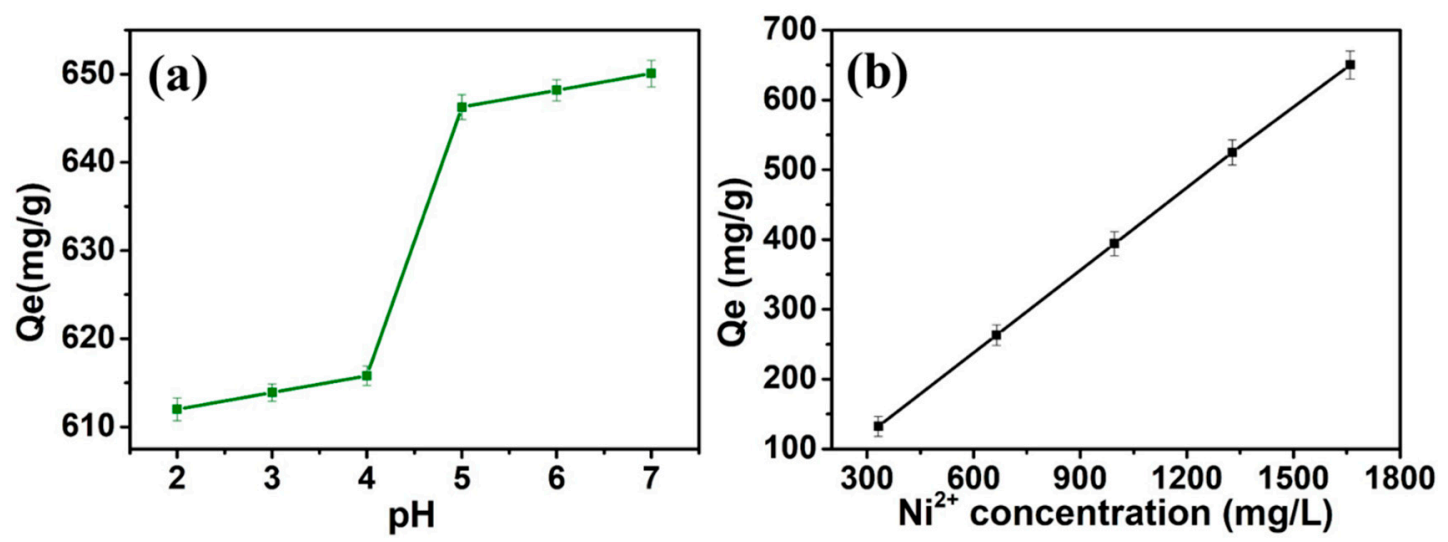

Figure 5. Effect of (a) $\mathrm{pH}(\mathbf{b})$ initial $\mathrm{Ni}^{2+}$ concentration on the adsorption capacity of gauze@PEI $\mathrm{P}_{0.4} /$ PEGDE $_{1} /$ TETA $_{0.6}$.

\subsubsection{Effect of Initial Concentration on $\mathrm{Ni}^{2+}$ Adsorption}

The effect of the initial concentration of $\mathrm{Ni}^{2+}$ towards the adsorption capacity of $\mathrm{Ni}^{2+}$ is investigated using various concentrations ranging from $300 \mathrm{mg} / \mathrm{L}$ to $1600 \mathrm{mg} / \mathrm{L}$. The investigation is performed at pH 7.0 for $90 \mathrm{~min}$ to ensure equilibrium is achieved. Figure $5 \mathrm{~b}$ clearly shows that the adsorption capacity of $\mathrm{Ni}^{2+}$ can be enhanced with increasing initial concentration of $\mathrm{Ni}^{2+}$. The result is attributed to the enhanced chelation between the adsorbent and $\mathrm{Ni}^{2+}$ ions. Moreover, the increase in the concentration of heavy metal ions will lead to enhanced ion adsorption. A similar phenomenon was reported Kesenci et al. [57].

\subsubsection{Adsorption Isotherms}

According to both experimental results for the adsorption of $\mathrm{Ni}^{2+}$ versus equilibrium concentration. Results were analyzed by the Freundlich and Langmuir equations at different temperatures [58]. Linear plots were obtained for both cases, revealing the Freundlich and Langmuir isotherms can be applied to the $\mathrm{Ni}^{2+}$ adsorption of this study. Langmuir and Freundlich plots for the $\mathrm{Ni}^{2+}$ adsorption are shown in Figure 6a,b, respectively. The derived Langmuir and Freundlich constants are listed in Table 1. In comparison with the Langmuir model, the Freundlich model demonstrated a better fit. It is worth noting that the correlation coefficient $\left(\mathrm{R}^{2}\right)$ for gauze@PEI ${ }_{0.4} / \mathrm{PEGDE}_{1} / \mathrm{TETA}_{0.6}$ presented in the Freundlich isotherms is closer to 1 when compared to the Langmuir isotherms. Thus, the adsorption process of $\mathrm{Ni}^{2+}$ tends to occur on the heterogeneous surface. 

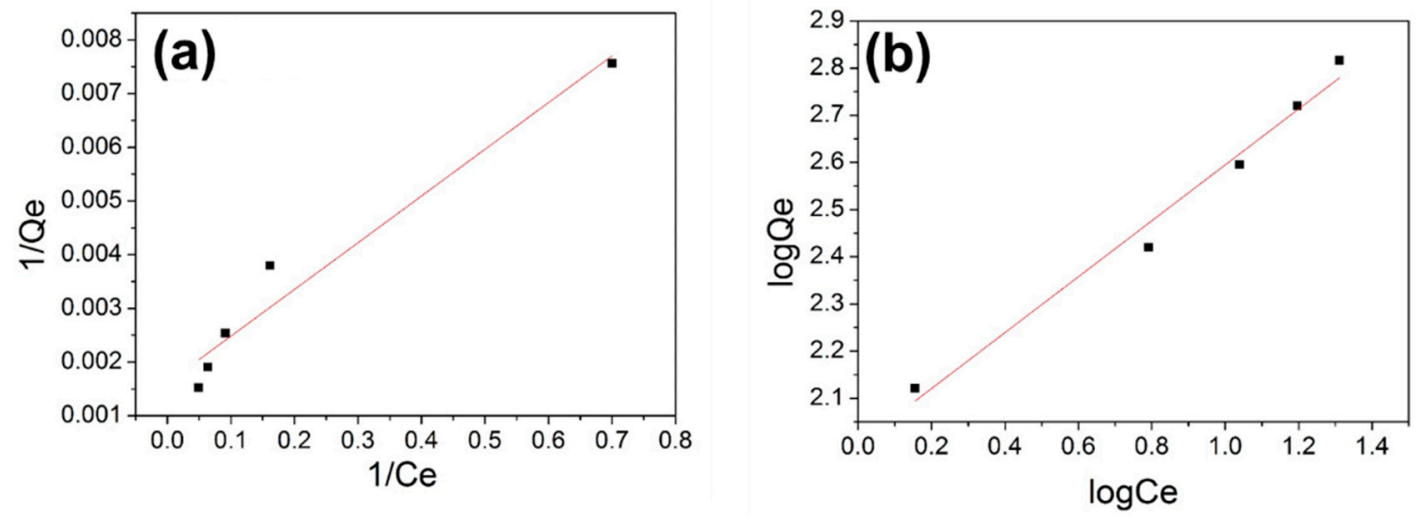

Figure 6. Adsorption isotherms of gauze@ $\mathrm{PEI}_{0.4} / \mathrm{PEGDE}_{1} / \mathrm{TETA}_{0.6}$ based on (a) the Langmuir isotherm model and (b) the Freundlich isotherm model.

Table 1. Freundlich and Langmuir isotherm constants.

\begin{tabular}{ccccccc}
\hline \multirow{2}{*}{ Adsorbent } & \multicolumn{3}{c}{ Langmuir Isotherm } & \multicolumn{3}{c}{ Freundlich Isotherm } \\
\cline { 2 - 7 } & $\begin{array}{c}\mathbf{Q}_{\mathbf{m}} \\
(\mathbf{m g} / \mathbf{g})\end{array}$ & $\begin{array}{c}\mathbf{K}_{\mathbf{L}} \\
(\mathbf{L} / \mathbf{m g})\end{array}$ & $\mathbf{R}^{2}$ & $\mathbf{K}_{\mathbf{F}}$ & $\mathbf{n}$ & $\mathbf{R}^{\mathbf{2}}$ \\
\hline gauze@PEI & & & & & \\
\hline
\end{tabular}

\subsubsection{Adsorption Kinetics}

The reactions and mechanism of the adsorption process can be investigated based on the adsorption kinetic data. Further, the adsorption kinetic data also provides the information on the adsorption of solutes at a solid-liquid interface which, in turn, is influenced by the residence time of $\mathrm{Ni}^{2+}$. The kinetic data were fitted in two types of the kinetic model including pseudo first-order and second-order models, as shown in Figure 7. Table 2 lists the results of the linear fitting. Hence, based on the correlation coefficient, the adsorption of $\mathrm{Ni}^{2+}$ on modified gauze is best described using a pseudo second-order model.
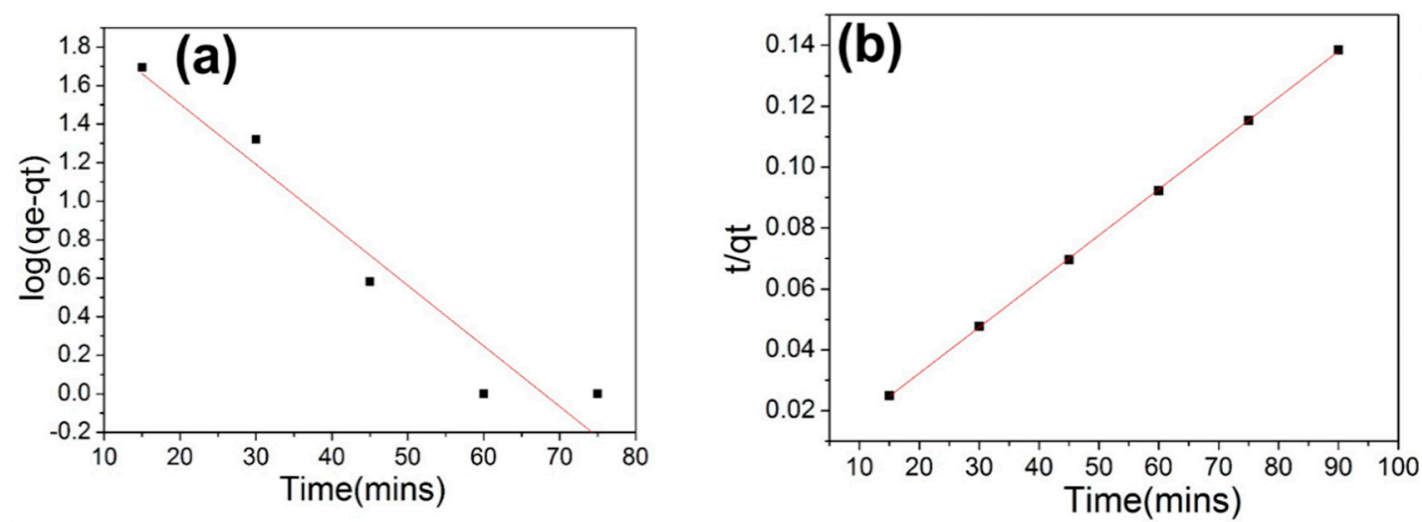

Figure 7. Adsorption kinetics of $\mathrm{Ni}^{2+}$ ions on gauze@PEI ${ }_{0.4} / \mathrm{PEGDE}_{1} / \mathrm{TETA}_{0.6}$ fitted in (a) pseudo first-order model and (b) pseudo second-order model.

Table 2. Parameters used for the kinetic model.

\begin{tabular}{ccccccc}
\hline \multirow{2}{*}{ Adsorbent } & \multicolumn{3}{c}{ Pseudo First-Order } & \multicolumn{3}{c}{ Pseudo Second-Order } \\
\cline { 2 - 7 } & $\mathbf{q}_{\mathbf{e}} \mathbf{( \mathbf { m g } / \mathbf { g } )}$ & $\mathbf{K}_{\mathbf{1}}\left(\mathbf{h}^{-\mathbf{1}}\right)$ & $\mathbf{R}^{\mathbf{2}}$ & $\mathbf{q}_{\mathbf{e}} \mathbf{( \mathbf { m g } / \mathbf { g } )}$ & $\mathbf{K}_{\mathbf{2}} \mathbf{( g / \mathbf { h } \mathbf { ~ m g } )}$ & $\mathbf{R}^{\mathbf{2}}$ \\
\hline $\begin{array}{c}\text { gauze@ } \\
\mathrm{PEI}_{0.4} / \mathrm{PEGDE}_{1} / \mathrm{TETA}_{0.6}\end{array}$ & 126 & 0.005 & 0.916 & 666 & 0.001 & 0.999 \\
\hline
\end{tabular}




\subsubsection{Effect of the Types and the Molar Ratio of Amine Monomers on $\mathrm{Ni}^{2+}$ Removal}

To check the influence of the structure of adsorbent on the adsorption capacity, a part of the PEI monomer is replaced by linear (TETA) or cyclic (BAP) amino monomers. The relationship between the molar ratio of both PEI/TETA and PEI/BAP with the adsorption efficiency is presented in Figure 8. The sample with a higher PEI content $\left(\mathrm{PEI}_{0.4} / \mathrm{PEGDE}_{1} / \mathrm{TETA}_{0.6}\right)$ demonstrated a higher adsorption capacity of $\mathrm{Ni}^{2+}$ than that of immobilized adsorbents with a lower PEI content $\left(\mathrm{PEI}_{0.2} / \mathrm{PEGDE}_{1} / \mathrm{TETA}_{0.8}\right)$. The better adsorption capacity of $\mathrm{PEI}_{0.4} / \mathrm{PEGDE}_{1} / \mathrm{TETA}_{0.6}$ is ascribed to the higher content of amino groups available on the polymer chain of $\mathrm{PEI}_{0.4} / \mathrm{PEGDE}_{1} / \mathrm{TETA}_{0.6}$ in comparison with that of $\mathrm{PEI}_{0.2} / \mathrm{PEGDE}_{1} / \mathrm{TETA}_{0.8}$. It is also reported in the research done by Chen et al. [59] where the adsorption capacity of TET-MRGO is enhanced after the incorporation of TETA when compared to pristine GO. The higher adsorption efficiency of triethylenetetramine magnetic-reduced graphene oxide composite (TET-MRGO) is due to the higher amount of $\mathrm{NH}_{2}$ - groups, which also acts as the binding sites for $\mathrm{Cu}$ (II) ions. Therefore, with the loading of TETA, the stability and adsorption capability of graphene oxide is greatly enhanced. The results proved that the composition (chemical structure) of the polymeric adsorbent not only affects the surface wettability, but also the absorption performance.

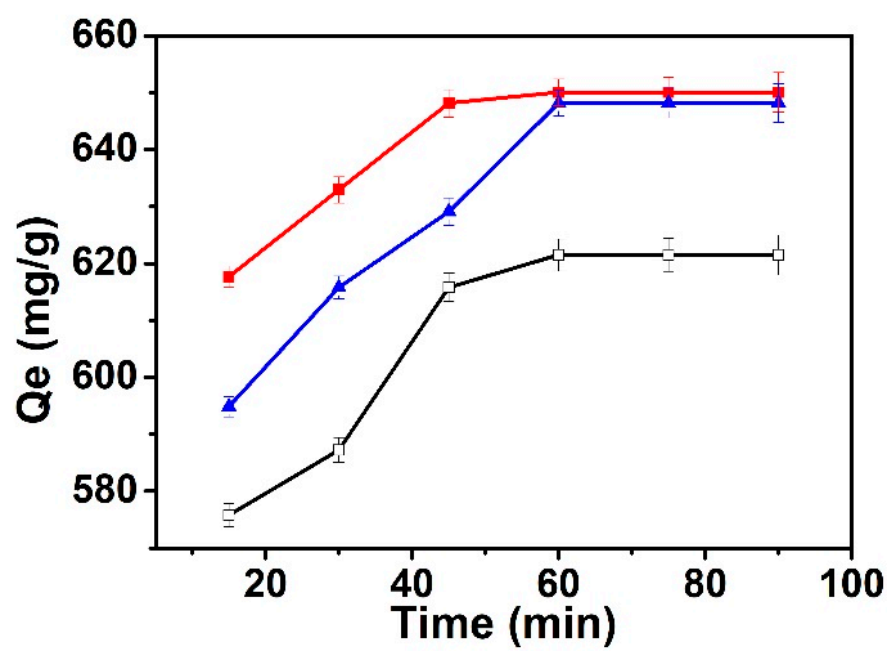

Figure 8. Adsorption capacity towards $\mathrm{Ni}^{2+}$ of gauze@PEI ${ }_{0.4} / \mathrm{PEGDE}_{1} / \mathrm{TETA}_{0.6}$ (匹); gauze@PEI $0.2 /$ $\mathrm{PEGDE}_{1} / \mathrm{TETA}_{0.8}(\square)$ and gauze@PEI $0.2 / \mathrm{PEGDE}_{1} / \mathrm{BAP}_{0.8}(\boldsymbol{\Delta})$.

Additionally, as seen in Figure 8, the adsorption capacity of $\mathrm{PEI}_{0.2} / \mathrm{PEGDE}_{1} / \mathrm{BAP}_{0.8}$ towards $\mathrm{Ni}^{2+}$ is significantly higher than that of $\mathrm{PEI}_{0.2} / \mathrm{PEGDE}_{1} / \mathrm{TETA}_{0.8}$. Hence, we can deduce that the immobilized adsorbents containing BAP amino groups are more preferably to undergo chelation with $\mathrm{Ni}^{2+}$ ions which in turn enhancing the removal of $\mathrm{Ni}^{2+}$ ions. Researchers found the ligand-to-metal charge-transfer (LMCT) caused by a transfer of electrons from the tertiary amine to the metal center. Yamamoto et al. observed the UV-VIS absorbance increases in poly(amidoamine) (PAMAM) dendrimers chelation of $\mathrm{Pt}^{2+}$, attributing them to LMCT [60]. This phenomenon can be interpreted as a transfer of electrons from the HOMO of the tertiary amine to the metal center LUMO, causing the compound to adapt its unique color. Mankbadi and coworkers [61] reported the chelation of iron ions by generation 4 hydroxyl-terminated PAMAM. It is a LMCT between the free electron group of the dendrimer's internal amines and the dehalogenated $\mathrm{Fe}^{3+}$ ion. In this study, there are two primary amine and two cyclic tertiary amine groups in a BAP monomer. There are two primary amine and two linear secondary amine groups in a TETA monomer. The results observed in this study reveals that BAP amino groups more preferably to undergo chelation with $\mathrm{Ni}^{2+}$ ions than TETA groups. The cyclic tertiary amine groups favor the ligand-to-metal charge-transfer.

Surprisingly, as seen in Figure 8, gauze@PEI $\mathrm{PE}_{0.4} / \mathrm{PEGDE}_{1} / \mathrm{TETA}_{0.6}$ exhibited the best adsorption capacity among all three immobilized adsorbents. Hence gauze@PEI $\mathrm{PI}_{0.4} / \mathrm{PEGDE}_{1} / \mathrm{TETA}_{0.6}$ is chosen to 
be used throughout the rest of the study. Nevertheless, the adsorption capacity of all three immobilized adsorbents increases with time and remains constant after $80 \mathrm{~min}$ as seen in Figure 8 . Thus, the reaction time for the rest of the experiments was carried out in a constant amount of time, $80 \mathrm{~min}$. It is worth noting that equilibrium can be reached within such a short period of contact time, suggesting that the adsorbents show an excellent affinity towards $\mathrm{Ni}^{2+}$ ions.

\subsection{Polymer/BiOBr-modified Gauzes as Dual-Functional Membranes}

\subsubsection{Morphology}

FESEM was used to study the morphology of polymer-modified gauze and polymer/BiOBrmodified gauze samples (Figure 9). In the case of polymer-modified gauze (Figure 9a), the fibers exhibit smooth surfaces. In addition to the coating on the fiber surface, some cavities among fibers were filled by the polymeric adsorbent. In comparison with the polymer modified gauze, polymer/BiOBr-modified gauze sample PB10 (Figure 9b) shows some BiOBr nanomaterials on the surface of some fibers. The presence of $\mathrm{BiOBr}$ in $\mathrm{PB} 10$ can be observed based on the light-colored areas. As the spraying time increases, the PB20 sample (Figure 9c) has more BiOBr nanomaterials on the surface than the PB10 sample. These $\mathrm{BiOBr}$ were well-dispersed on the surface with minor agglomeration. For the PB30 sample (Figure 9d), the higher amount of BiOBr causes agglomeration of the particles on the fiber surface. The surface turned from smooth to rough as the spraying time increase. Figure 9e presents the $\mathrm{N}, \mathrm{C}, \mathrm{Bi}, \mathrm{O}, \mathrm{Br}$ elemental mapping images of PB30. The elemental mapping imaging of nitrogen $(\mathrm{N})$ proved that the uniform distribution of the amine functional group of the polymeric adsorbent on the gauze. Additionally, the elemental mapping of $\mathrm{Bi}, \mathrm{O}$, and $\mathrm{Br}$ confirmed the decoration of $\mathrm{BiOBr}$ on the surface of the polymer-coated gauze.
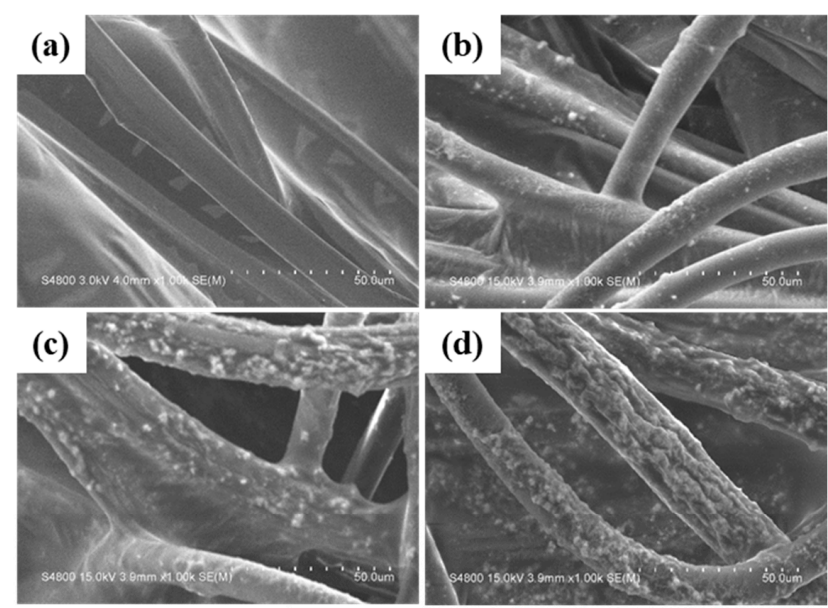

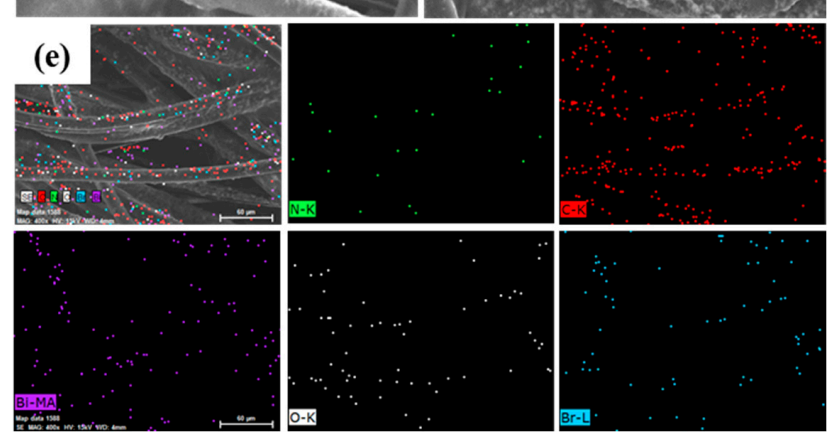

Figure 9. FESEM images of polymer-modified gauze (a) $\mathrm{P}$, and polymer/BiOBr-modified gauze samples prepared by changing the time for spray coating (10, 20, 30 s) (b) PB10, (c) PB20, (d) PB30, and (e) elemental N, C, Bi, O, Br mapping images of PB30. 


\subsubsection{Dynamic Contact Angle (DCA)}

As shown in Figure 1, the complete wetting time for the polymer-modified gauze membrane gauze@PEI $\mathrm{PL}_{0.4} / \mathrm{PEGDE}_{1} / \mathrm{TETA}_{0.6}$ is $4 \mathrm{~s}$. However, the decoration of $\mathrm{BiOBr}$ makes the membranes even more hydrophilic. Figure 10 presents the initial images of (a) PB10 (c) PB20 (e) PB30 and dynamic contact angle images of the time required for the complete wetting of water droplets on various polymer/BiOBr-coated gauze (b) PB10 (d) PB20 (f) PB30. All three polymer/BiOBr-modified gauze membranes with different amounts of $\mathrm{BiOBr}$ can be completely wetted within $0.01 \mathrm{~s}$.

$0 \mathrm{~s}$

(a)
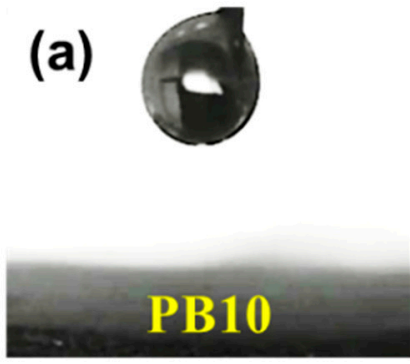

(c)
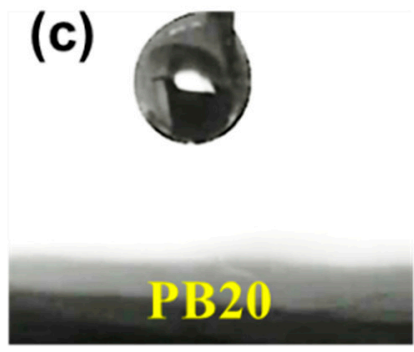

(e)

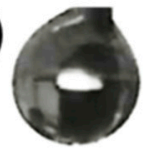

\section{PB30}

\section{$0.01 \mathrm{~s}$}

(b)

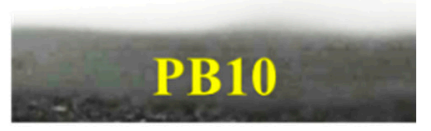

(d)

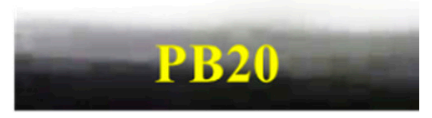

(f)

\section{PB30}

Figure 10. Initial images of (a) PB10 (c) PB20 (e) PB30 and dynamic contact angle images of the time required for the complete wetting of water droplets on various polymer/BiOBr-coated gauze (b) $\mathrm{PB} 10$ (d) PB20 (f) PB30.

\subsubsection{Photocatalytic Decolorization Performance}

The RhB dye was selected to survey the photocatalytic activity of the polymer-modified gauze, and polymer/BiOBr-modified gauze samples (PB10, PB20, PB30). Photodegradation curves are demonstrated in Figure 11. The control experiment was performed without adding any BiOBr photocatalyst on polymer-modified gauze $(\mathrm{P})$ to realize the decolorization nature of $\mathrm{P}$ under the irradiation of light. From the blank experiment, it is revealed that RhB was not decolorized by $\mathrm{P}$ under the light irradiation. The decoration of $\mathrm{BiOBr}$ on the adsorbent layer introduces the photocatalytic activity. It takes $120 \mathrm{~min}$ for 100\% degradation of RhB by PB10. PB20 and PB30 showed excellent photocatalytic activity with 100\% degradation of RhB over 70 min than that of PB10 (78\% degradation). PB30 with more BiOBr did not show better activity than PB20 with fewer BiOBr. As demonstrated in Figure $9 \mathrm{~d}$, agglomeration of the $\mathrm{BiOBr}$ particles was found on the fiber surface. The effective surface 
active area of $\mathrm{BiOBr}$ cannot increase because of the agglomeration. This may be the reason why PB20 and PB30 showed similar photocatalytic activity.

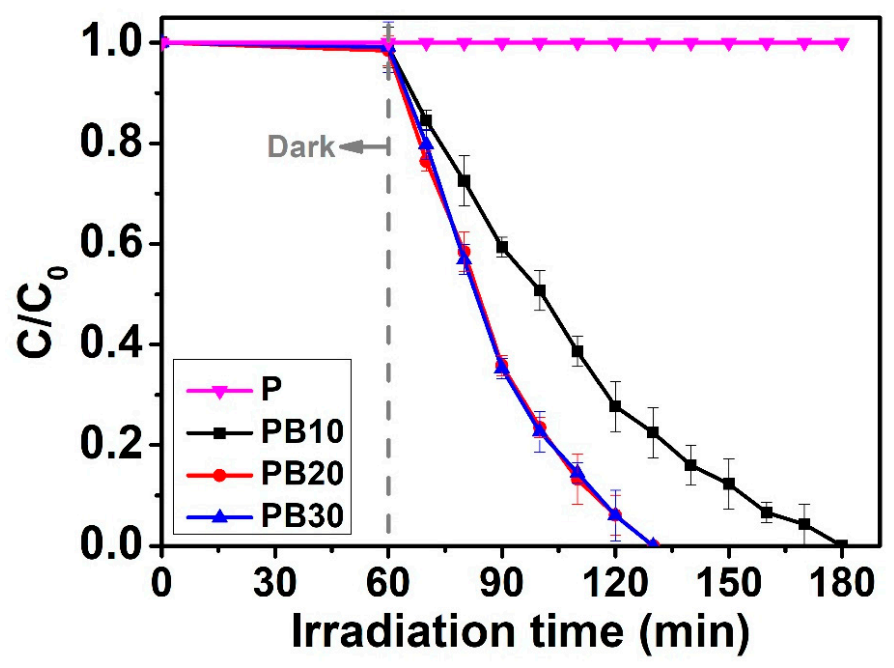

Figure 11. Photodegradation curves of $\mathrm{RhB}$ over polymer-modified gauze $(\mathrm{P})$, and polymer/BiOBrmodified gauze samples (PB10, PB20, PB30).

\subsubsection{Effect of BiOBr Decorization on $\mathrm{Ni}^{2+}$ Removal}

Adsorption capacity towards $\mathrm{Ni}^{2+}$ of polymer-modified gauze $(\mathrm{P})$, and polymer/BiOBr-modified gauze samples (PB10, PB20, PB30) are shown in Figure 12. The control experiment was performed without adding any $\mathrm{BiOBr}$ photocatalyst on polymer-modified gauze $(\mathrm{P})$ to realize the $\mathrm{Ni}^{2+}$ adsorption capacity of P. From the blank experiment, it is revealed that $\mathrm{P}$ possesses excellent adsorption capacity of $650 \mathrm{mg} \mathrm{g}^{-1}$ for $\mathrm{Ni}^{2+}$ ions. After the decoration of $\mathrm{BiOBr}$ on the adsorbent layer, the area of exposed polymeric adsorbent $\left(\mathrm{PEI}_{0.4} / \mathrm{PEGDE}_{1} / \mathrm{TETA}_{0.6}\right)$ decreased. The results in Figure 12 showed that PB10 and PB20 samples had similar $\mathrm{Ni}^{2+}$ adsorption capacity $\left(650 \mathrm{mg} \mathrm{g}^{-1}\right)$ as $\mathrm{P}$. However, the $\mathrm{Ni}^{2+}$ adsorption capacity of PB30 decreased to $620 \mathrm{mg} \mathrm{g}^{-1}$. The decreased area of exposed polymeric adsorbent may be the reason for the decreased adsorption capacity. Considering the compromise between photocatalytic activity and $\mathrm{Ni}^{2+}$ adsorption capacity, PB20 is the optimized dual-functional polymer/BiOBr-modified gauze membrane.

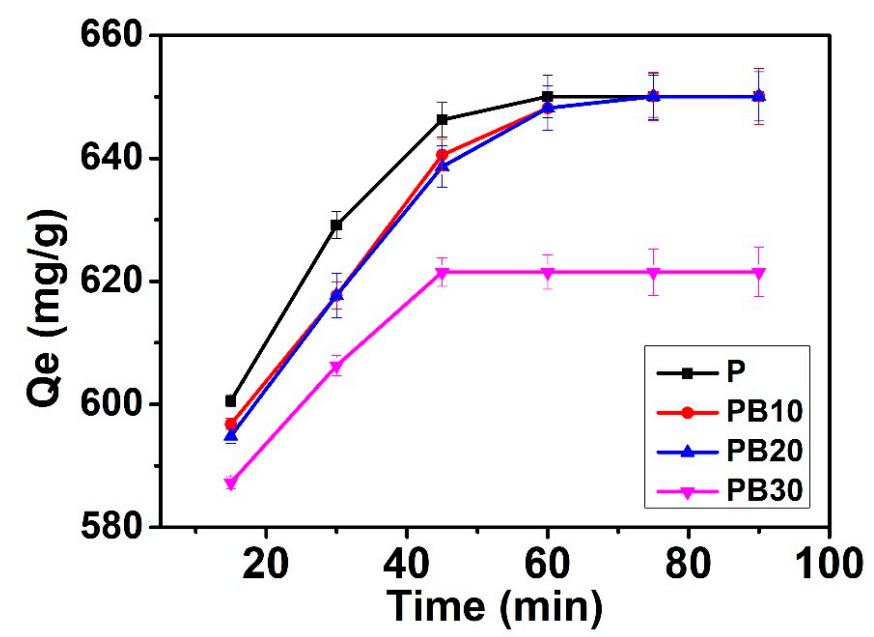

Figure 12. Adsorption capacity towards $\mathrm{Ni}^{2+}$ of polymer-modified gauze $(\mathrm{P})$, and polymer/BiOBrmodified gauze samples (PB10, PB20, PB30). 


\section{Conclusions}

In this study, polymer/BiOBr-modified gauzes were developed as dual-functional membranes for the removal of organic dyes and heavy metal ions. The gauze substrate was surface-modified by coating with a polymeric adsorbent consisting of hydrophilic diepoxy (PEGDE), a crosslinking agent (PEI), and diamine (TETA) to develop a novel dual-functional photocatalyst and adsorbent membrane for water remediation. Since all monomers are well soluble in water, the coating was crosslinked to prevent the dissolving of the adsorbent on the polymer-modified gauze during operation in contaminated water. For the gauze@PEI $\mathrm{P}_{0.4} / \mathrm{PEGDE}_{1} / \mathrm{TETA}_{0.6}$ membrane, the adsorption isotherms were better described by the Freundlich model. The XPS results revealed that $\mathrm{Ni}^{2+}$ acquired electrons and formed a complex between $\mathrm{Ni}$ and $\mathrm{NH}_{2}$ during the $\mathrm{Ni}^{2+}$ adsorption process. The maximum uptake of $\mathrm{Ni}^{2+}$ ions is achieved at $\mathrm{pH}$ 7. The adsorption capacity of $\mathrm{Ni}^{2+}$ increases with the increase in the initial concentration of $\mathrm{Ni}^{2+}$. The monomer molar ratio and monomer chemical structure each show a great influence on the $\mathrm{Ni}^{2+}$ adsorption capacity. Then, $\mathrm{BiOBr}$ was dispersed in ethanol and deposited on the polymer-modified gauze by spray-coating to obtain the polymer/BiOBr-modified gauze. To achieve a high $\mathrm{Ni}^{2+}$ adsorption capacity and good photocatalytic decolorization activity, the amount of decorated $\mathrm{BiOBr}$ was tuned by changing the spray-coating time to optimize the exposed $\mathrm{BiOBr}$ and polymer on the surface. The amount of $\mathrm{BiOBr}$ on the surface increased with increasing the spray coating time. The optimized dual-functional membrane PB20 possesses an excellent adsorption capacity $\left(650 \mathrm{mg} \mathrm{g}^{-1}\right)$ for $\mathrm{Ni}^{2+}$ ions and photocatalytic decolorization activity (100\% degradation of $\mathrm{RhB}$ within $70 \mathrm{~min}$ ). Decorating the optimized amount of $\mathrm{BiOBr}$ on the surface can introduce photocatalytic decolorization activity without sacrificing the adsorption capacity for $\mathrm{Ni}^{2+}$. Polymer/BiOBr-modified gauze has great potentials in the remediation of wastewater containing organic pollutants and heavy metals.

Author Contributions: Conceptualization: C.-J.C.; methodology: C.-J.C.; validation, formal analysis: P.-Y.C., Y.-J.C., and C.-Y.C.; investigation: C.-J.C. and C.-F.H.; data curation: P.-Y.C. and C.-Y.C.; writing: C.-J.C.; supervision, project administration: C.-J.C. All authors have read and agreed to the published version of the manuscript.

Funding: This research was funded by the Ministry of Science and Technology under the contract of MOST 108-2221-E-035-049-MY3.

Acknowledgments: The authors appreciate the Precision Instrument Support Center of Feng Chia University in providing the measurement facilities.

Conflicts of Interest: The authors declare no conflict of interest.

\section{References}

1. De Oliveira, F.M.; Somera, B.F.; Ribeiro, E.S.; Segatelli, M.G.; Santos Yabe, M.J.; Galunin, E.; Tarley, C.R.T. Kinetic and isotherm studies of $\mathrm{Ni}^{2+}$ adsorption on poly (methacrylic acid) synthesized through a hierarchical double-imprinting method using a $\mathrm{Ni}^{2+}$ ion and cationic surfactant as templates. Ind. Eng. Chem. Res. 2013, 52, 8550-8557. [CrossRef]

2. Cempel, M.; Nikel, G. Nickel: A Review of Its Sources and Environmental Toxicology. Polish J. Environ. Stud. 2006, 15, 375 .

3. Yebra, M.C.; Cancela, S.; Cespón, R.M. Automatic Determination of Nickel in Foods by Flame Atomic Absorption Spectrometry. Food Chem. 2008, 108, 774. [CrossRef] [PubMed]

4. Janaki, V.; Oh, B.T.; Shanthi, K.; Lee, K.J.; Ramasamy, A.K.; Kamala-Kannan, S. Polyaniline/chitosan composite: An eco-friendly polymer for enhanced removal of dyes from aqueous solution. Synth. Met. 2012, 162, 974-980. [CrossRef]

5. Annadurai, G.; Ling, L.Y.; Lee, J.F. Adsorption of reactive dye from an aqueous solution by chitosan: Isotherm, kinetic and thermodynamic analysis. J. Hazard. Mater. 2008, 15, 337-346. [CrossRef]

6. Tan, P.; Sun, J.; Hu, Y.; Fang, Z.; Bi, Q.; Chen, Y.; Cheng, J. Adsorption of $\mathrm{Cu}^{2+}, \mathrm{Cd}^{2+}$ and $\mathrm{Ni}^{2+}$ from aqueous single metal solutions on graphene oxide membranes. J. Hazard. Mater. 2015, 297, 251-260. [CrossRef]

7. Hung, S.T.; Chang, C.J.; Hsu, M.H. Improved photocatalytic performance of ZnO nanograss decorated pore-array films by surface texture modification and silver nanoparticle deposition. J. Hazard. Mater. 2011, 198, 307-316. [CrossRef] 
8. Dotto, G.L.; Pinto, L.A.A. Adsorption of food dyes acid blue 9 and food yellow 3 onto chitosan: Stirring rate effect in kinetics and mechanism. J. Hazard. Mater. 2011, 187, 164-170. [CrossRef]

9. Chang, C.J.; Lin, C.Y.; Hsu, M.H. Enhanced photocatalytic activity of Ce-doped ZnO nanorods under UV and visible light. J. Taiwan Inst. Chem. E 2014, 45, 1954-1963. [CrossRef]

10. Alnuaimi, M.M.; Rauf, M.A.; Ashraf, S.S. Comparative decoloration study of Neutral Red by different oxidative processes. Dyes Pigments 2007, 72, 367-371. [CrossRef]

11. Chang, C.J.; Yang, T.L.; Weng, Y.C. Synthesis and characterization of Cr-doped ZnO nanorod-array photocatalysts with improved activity. J. Solid State Chem. 2014, 214, 101-107. [CrossRef]

12. Wong, C.W.; Barford, J.P.; Chen, G.; McKay, G. Kinetics and equilibrium studies for the removal of cadmium ions by ion exchange resin. J. Environ. Chem. Eng. 2014, 2, 698-707. [CrossRef]

13. Chen, T.; Liu, F.; Ling, C.; Gao, J.; Xu, C.; Li, L.; Li, A. Insight into highly efficient coremoval of copper and p-nitrophenol by a newly synthesized polyamine chelating resin from aqueous media: Competition and enhancement effect upon site recognition. Environ. Sci. Technol. 2013, 47, 13652-13660. [CrossRef] [PubMed]

14. Alvarez, M.T.; Crespo, C.; Mattiasson, B. Precipitation of $\mathrm{Zn}(\mathrm{II}), \mathrm{Cu}(\mathrm{II})$ and $\mathrm{Pb}(\mathrm{II})$ at bench-scale using biogenic hydrogen sulfide from the utilization of volatile fatty acids. Chemosphere 2007, 66, 1677-1683. [CrossRef] [PubMed]

15. Fu, F.; Xie, L.; Tang, B.; Wang, Q.; Jiang, S. Application of a novel strategy-Advanced Fenton-chemical precipitation to the treatment of strong stability chelated heavy metal containing wastewater. Chem. Eng. J. 2012, 189, 283-287. [CrossRef]

16. Chu, K.W.; Lee, S.L.; Chang, C.J.; Liu, L. Recent progress of carbon dot precursors and photocatalysis applications. Polymers 2019, 11, 689. [CrossRef]

17. Chang, C.J.; Chen, J.K.; Lin, K.S.; Wei, Y.H.; Chao, P.Y.; Huang, C.Y. Enhanced visible-light-driven photocatalytic degradation by metal wire-mesh supported $\mathrm{Ag} /$ flower-like $\mathrm{Bi}_{2} \mathrm{WO}_{6}$ photocatalysts. J. Alloys Compd. 2020, 813, 152186. [CrossRef]

18. Hsu, M.H.; Chang, C.J. Ag-doped ZnO nanorods coated metal wire meshes as hierarchical photocatalysts with high visible-light driven photoactivity and photostability. J. Hazard. Mater. 2014, 278, 444-453. [CrossRef]

19. Espinoza, I.; Pauker, C.S.; Guerrero, L.R.; Jentzsch, P.V.; Bisesti, F.M. Fenton process combined with precipitation for the removal of Direct Blue 1 dye: A new approach. J. Serb. Chem. Soc. 2020, 85, 547-558. [CrossRef]

20. Zhu, W.P.; Gao, J.; Sun, S.P.; Zhang, S.; Chung, T.S. Poly(amidoamine) dendrimer (PAMAM) grafted on thin film composite (TFC) nanofiltration (NF) hollow fiber membranes for heavy metal removal. J. Membr. Sci. 2015, 487, 117-126. [CrossRef]

21. Maher, A.; Sadeghi, M.; Moheb, A. Heavy metal elimination from drinking water using nanofiltration membrane technology and process optimization using response surface methodology. Desalination 2014, 352, 166-173. [CrossRef]

22. Otrembska, P.; Gega, J. Separation of nickel (II) and cadmium (II) ions with ion-exchange and membrane processes. Sep. Sci. Technol. 2016, 51, 2675-2680. [CrossRef]

23. Cui, L.; Wang, Y.; Gao, L.; Hu, L.; Yan, L.; Wei, Q.; Du, B. EDTA functionalized magnetic graphene oxide for removal of $\mathrm{Pb}(\mathrm{II}), \mathrm{Hg}(\mathrm{II})$ and $\mathrm{Cu}(\mathrm{II})$ in water treatment: Adsorption mechanism and separation property. Chem. Eng. J. 2015, 281, 1-10. [CrossRef]

24. Vakili, M.; Deng, S.; Cagnetta, G.; Wang, W.; Meng, P.; Liu, D.; Yu, G. Regeneration of chitosan-based adsorbents used in heavy metal adsorption: A review. Sep. Purif. Technol. 2019, 224, 373-387. [CrossRef]

25. Chowdhury, I.H.; Chowdhury, A.H.; Bose, P.; Mandal, S.; Naskar, M.K. Effect of anion type on the synthesis of mesoporous nanostructured $\mathrm{MgO}$, and its excellent adsorption capacity for the removal of toxic heavy metal ions from water. RSC Adv. 2016, 6, 6038-6604. [CrossRef]

26. Deng, J.H.; Zhang, X.R.; Zeng, G.M.; Gong, J.L.; Niu, Q.Y.; Liang, J. Simultaneous removal of Cd (II) and ionic dyes from aqueous solution using magnetic graphene oxide nanocomposite as an adsorbent. Chem. Eng. J. 2013, 226, 189-200. [CrossRef]

27. Liu, Q.; Li, Y.; Chen, H.; Lu, J.; Yu, G.; Möslang, M.; Zhou, Y. Superior adsorption capacity of functionalised straw adsorbent for dyes and heavy-metal ions. J. Hazard. Mater. 2020, 382, 121040. [CrossRef]

28. Hou, H.; Zhou, R.; Wu, P.; Wu, L. Removal of Congo red dye from aqueous solution with hydroxyapatite/ chitosan composite. Chem. Eng. J. 2012, 211, 336-342. [CrossRef] 
29. Chen, B.; Chen, S.; Zhao, H.; Liu, Y.; Long, F.; Pan, X. A versatile $\beta$-cyclodextrin and polyethyleneimine bi-functionalized magnetic nanoadsorbent for simultaneous capture of methyl orange and $\mathrm{Pb}$ (II) from complex wastewater. Chemosphere 2019, 216, 605-616. [CrossRef]

30. Skold, M.E.; Thyne, G.D.; Drexler, J.W.; Macalady, D.L.; McCray, J.E. Enhanced Solubilization of a MetalOrganic Contaminant Mixture (Pb, Sr, Zn, and Perchloroethylene) by Cyclodextrin. Environ. Sci. Technol. 2008, 42, 8930-8934. [CrossRef]

31. Wan, W.; Xing, Y.; Qin, X.; Li, X.; Liu, S.; Luo, X.; Huang, Q.; Chen, W. A manganese-oxidizing bacterial consortium and its biogenic Mn oxides for dye decolorization and heavy metal adsorption. Chemosphere 2020, 126627. [CrossRef] [PubMed]

32. Zhao, F.; Repo, E.; Yin, D.; Meng, Y.; Jafari, S.; Sillanpää, M. EDTA-cross-linked $\beta$-cyclodextrin: An environmentally friendly bifunctional adsorbent for simultaneous adsorption of metals and cationic dyes. Environ. Sci. Technol. 2015, 49, 10570-10580. [CrossRef] [PubMed]

33. Kyzas, G.Z.; Siafaka, P.I.; Pavlidou, E.G.; Chrissafis, K.J.; Bikiaris, D.N. Synthesis and adsorption application of succinyl-grafted chitosan for the simultaneous removal of zinc and cationic dye from binary hazardous mixtures. Chem. Eng. J. 2015, 259, 438-448. [CrossRef]

34. Fu, F.; Han, W.; Tang, B.; Hu, M.; Cheng, Z. Insights into environmental remediation of heavy metal and organic pollutants: Simultaneous removal of hexavalent chromium and dye from wastewater by zero-valent iron with ligand-enhanced reactivity. Chem. Eng. J. 2013, 232, 534-540. [CrossRef]

35. Tovar-Gomez, R.; Rivera-Ramírez, D.A.; Hernandez-Montoya, V.; Bonilla-Petriciolet, A.; Durán-Valle, C.J.; Montes-Morán, M.A. Synergic adsorption in the simultaneous removal of acid blue 25 and heavy metals from water using a $\mathrm{Ca}\left(\mathrm{PO}_{3}\right)_{2}$-modified carbon. J. Hazard. Mater. 2012, 199, 290-300. [CrossRef]

36. Lee, S.L.; Chang, C.J. Recent developments about conductive polymer based composite photocatalysts. Polymers 2019, 11, 206. [CrossRef]

37. Xu, Y.; Ma, Y.; Ji, X.; Huang, S.; Xia, J.; Xie, M.; Yan, J.; Xu, H.; Li, H. Conjugated conducting polymers PANI decorated $\mathrm{Bi}_{12} \mathrm{O}_{17} \mathrm{Cl}_{2}$ photocatalyst with extended light response range and enhanced photoactivity. Appl. Surf. Sci. 2019, 464, 552-561. [CrossRef]

38. Yu, W.J.; Cheng, Y.; Zou, T.; Liu, Y.; Wu, K.; Peng, N. Preparation of $\mathrm{BiPO}_{4}-$ Polyaniline Hybrid and its Enhanced Photocatalytic Performance. Nano 2018, 13, 1850009. [CrossRef]

39. Chang, C.J.; Tsai, M.H.; Hsu, Y.H.; Tuan, C.S. Morphology and optoelectronic properties of ZnO rod array/conjugated polymer hybrid films. Thin Solid Films 2008, 516, 5523-5526. [CrossRef]

40. Chang, C.J.; Chu, K.W. ZnS/polyaniline composites with improved dispersing stability and high photocatalytic hydrogen production activity. Int. J. Hydrogen Energy 2016, 41, 21764-21773. [CrossRef]

41. Yan, C.; Zhang, Z.; Wang, W.; Ju, T.; She, H.; Wang, Q. Synthesis and characterization of polyaniline-modified BiOI: A visible-light-response photocatalyst. J. Mater. Sci. Mater. Electron. 2018, 29, 18343-18351. [CrossRef]

42. Chang, C.J.; Hung, S.T. Electrochemical deposition of $\mathrm{ZnO}$ pore-array structures and photoconductivity of $\mathrm{ZnO}$ /polymer hybrid films. Thin Solid Films 2008, 517, 1279-1283. [CrossRef]

43. Tsai, M.H.; Lin, Y.K.; Chang, C.J.; Chiang, P.C.; Yeh, J.M.; Chiu, W.M.; Huang, S.L.; Ni, S.C. Polyimide modified with metal coupling agent for adhesion application. Thin Solid Films 2009, 517, 5333-5337. [CrossRef]

44. Wang, C.; Hu, Z.Y.; Zhao, H.; Yu, W.; Wu, S.; Liu, J.; Chen, L.; Li, Y. Probing conducting polymers@cadmium sulfide core-shell nanorods for highly improved photocatalytic hydrogen production. J. Colloid Interface Sci. 2018, 521, 1-10. [CrossRef] [PubMed]

45. Liu, X.; Cai, L. Novel indirect Z-scheme photocatalyst of Ag nanoparticles and polymer polypyrrole co-modified BiOBr for photocatalytic decomposition of organic pollutants. Appl. Surf. Sci. 2018, 445, 242-254. [CrossRef]

46. Wang, X.; Min, M.; Liu, Z.; Yang, Y.; Zhou, Z.; Zhu, M.; Chen, Y.; Hsiao, B.S. Poly (ethyleneimine) nanofibrous affinity membrane fabricated via one step wet-electrospinning from poly (vinyl alcohol)-doped poly (ethyleneimine) solution system and its application. J. Membrane Sci. 2011, 379, 191-199. [CrossRef]

47. Liu, B.; Huang, Y. Polyethyleneimine modified eggshell membrane as a novel biosorbent for adsorption and detoxification of Cr (VI) from water. J. Mater. Chem. 2011, 21, 17413-17418. [CrossRef]

48. Wang, J.; Li, Z. Enhanced selective removal of $\mathrm{Cu}$ (II) from aqueous solution by novel polyethyleniminefunctionalized ion imprinted hydrogel: Behaviors and mechanisms. J. Hazard. Mater. 2015, 300, 18-28. [CrossRef] 
49. Cao, C.Y.; Qu, J.; Yan, W.S.; Zhu, J.F.; Wu, Z.Y.; Song, W.G. Low-cost synthesis of flowerlike $\alpha-\mathrm{Fe}_{2} \mathrm{O}_{3}$ nanostructures for heavy metal ion removal: Adsorption property and mechanism. Langmuir 2012, 28, 4573-4579. [CrossRef]

50. Thakur, S.; Das, G.; Raul, P.K.; Karak, N. Green one-step approach to prepare sulfur/reduced graphene oxide nanohybrid for effective mercury ions removal. J. Phys. Chem. C 2013, 117, 7636-7642. [CrossRef]

51. Şölener, M.; Tunali, S.; Özcan, A.S.; Özcan, A.; Gedikbey, T. Adsorption characteristics of lead (II) ions onto the clay/poly (methoxyethyl) acrylamide (PMEA) composite from aqueous solutions. Desalination 2008, 223, 308-322. [CrossRef]

52. Li, J.; Chen, C.; Zhao, Y.; Hu, J.; Shao, D.; Wang, X. Synthesis of water-dispersible $\mathrm{Fe}_{3} \mathrm{O}_{4} @ \beta$-cyclodextrin by plasma-induced grafting technique for pollutant treatment. Chem. Eng. J. 2013, 229, 296-303. [CrossRef]

53. Li, X.; Zhou, H.; Wu, W.; Wei, S.; Xu, Y.; Kuang, Y. Studies of heavy metal ion adsorption on Chitosan/ Sulfydryl-functionalized graphene oxide composites. J. Colloid Int. Sci. 2015, 448, 389-397. [CrossRef] [PubMed]

54. Cheng, Y.; Shen, P.K.; Jiang, S.P. NiOx nanoparticles supported on polyethylenimine functionalized CNTs as efficient electrocatalysts for supercapacitor and oxygen evolution reaction. Int. J. Hydrogen Energy 2014, 39, 20662-20670. [CrossRef]

55. Ahmed, M.S.; Jeon, S. Synthesis and electrocatalytic activity evaluation of nanoflower shaped Ni-Pd on alcohol oxidation reaction. J. Electrochem. Soc. 2014, 161, 1300-1306. [CrossRef]

56. Zhang, Y.; Yan, T.; Yan, L.; Xiao, X.; Cui, L.; Wei, Q.; Du, B. Preparation of novel cobalt ferrite/chitosan grafted with graphene composite as effective adsorbents for mercury ions. J. Mol. Liq. 2014, 198, 381-387. [CrossRef]

57. Kesenci, K.; Say, R.; Denizli, A. Removal of heavy metal ions from water by using poly (ethyleneglycol dimethacrylate-co-acrylamide) beads. Eur. Polym. J. 2002, 38, 1443-1448. [CrossRef]

58. Mittal, A.; Kurup, L.; Mittal, J. Freundlich and Langmuir adsorption isotherms and kinetics for the removal of Tartrazine from aqueous solutions using hen feathers. J. Hazard. Mater. 2007, 146, 243-248. [CrossRef]

59. Chen, J.H.; Xing, H.T.; Sun, X.; Su, Z.B.; Huang, Y.H.; Weng, W.; Hu, S.R.; Guo, H.X.; Wu, W.B.; He, Y.S. Highly effective removal of $\mathrm{Cu}$ (II) by triethylenetetramine-magnetic reduced graphene oxide composite. Appl. Surf. Sci. 2015, 356, 355-363. [CrossRef]

60. Yamamoto, D.; Watanabe, S.; Miyahara, M.T. Coordination and reduction processes in the synthesis of dendrimer-encapsulated Pt nanoparticles. Langmuir 2010, 26, 2339-2345. [CrossRef]

61. Mankbadi, M.R.; Barakat, M.A.; Ramadan, M.H.; Woodcock, H.L.; Kuhn, J.N. Iron chelation by polyamidoamine dendrimers: A second-order kinetic model for metal-amine complexation. J. Phys. Chem. B 2011, 115, 13534-13540. [CrossRef] [PubMed]

(C) 2020 by the authors. Licensee MDPI, Basel, Switzerland. This article is an open access article distributed under the terms and conditions of the Creative Commons Attribution (CC BY) license (http://creativecommons.org/licenses/by/4.0/). 